DRUŠ. ISTRAŽ. ZAGREB

GOD. 20 (2011)

STR. 271-290 duboko prožeta trenutačnim ciljevima ekonomske struke. Kako navodi Jackson, preostaju "enklave kulturne misli koje su preživjele heterodoksne ekonomske i neekonomske društvene znanosti", no one nemaju gotovo nikakav utjecaj na ekonomsku ortodoksnost. Premda je riječ o svojevrsnoj obeshrabrujućoj viziji, s obzirom na Jacksonovu ustrajnost i uvjerljivost $\mathrm{u}$ njegovu primjeru upozoravanja na potrebu za aktivnijom ulogom kulturnog razmišljanja u ekonomiji, knjiga "Economics, Culture and Social Theory" pruža dobru mogućnost, priliku za tumačenje temeljnih kritika ekonomije, što je većina recentnih kritičara, u knjizi obrađivanih tema / područja, uglavnom propustila učiniti.

"Economics, Culture and Social Theory" Williama A. Jacksona knjiga je koja istražuje kako je kultura zanemarivana $u$ ekonomskim teoretiziranjima i razmatra kako bi ekonomija mogla imati koristi od uključivanja ideja iz socijalne i kulturne teorije. Ortodoksni ekonomisti potaknuli su dugogodišnju kritiku kulture, koja seže do početaka ekonomske teorije i proteže se na nedavne rasprave oko postmodernizma. Jackson u svojoj knjizi raspravlja o ekonomskoj kritici kulture, identificira glavne argumente i ocjenjuje njihove implikacije. Crpeći iz raznovrsne i brojne literature, posebice socijalne i kulturne teorije, knjiga "Economics, Culture and Social Theory" naglašava važnost kulture za ekonomsko ponašanje i razmatra planove, perspektive za obnovljene i kulturno informirane ekonomije. Ta je knjiga vrijedna za heterodoksne ekonomiste i svakoga tko je zainteresiran za veze između kulture i ekonomije. Temelji se na interdisciplinarnom pristupu, govori protiv izolacije ekonomije, pa valja pretpostaviti da bi mogla imati širok odjek među znanstvenicima društvenih disciplina, koji rade na srodnim poljima, te gospodarstvenicima specijaliziranima za kulturne ekonomije i ekonomske metodologije.

Damir Demonja

\section{doi:10.5559/di.20.1.16 \\ Daniela Angelina Jelinčić KULTURA U IZLOGU}

Meandarmedia, Biblioteka INTERMEDIA, knjiga 29, Zagreb, 2010., 127 str.

Kulturni se turizam u zadnjih dvadesetak godina u Hrvatskoj veoma mnogo spominje, prije svega kao smjer u kojem bi se naša turistička ponuda trebala razvijati, jer imamo, kažu naši turistički stratezi, štošta na tom polju ponuditi. No unatoč tome, neki smatraju da je kulturni turizam postao poštapalica u kontekstu ekonomije kulture, ali da kulturni turizam ne gubi na snazi s obzirom na to da je $u$ prisnom odnosu s kulturnim industrijama. Logično je da turistička ponuda i kulturne industrije uključuju proizvodnju i dinamički su procesi, a kulturna se baština asocira, s druge strane, statičnošću vezanom uz povijest.

Do sada se literatura koja je vezana uz kulturna dobra i baštinu najvećim dijelom bavila temama vezanima uz njihovu konzervaciju, rijetko promišljajući kako dodati dinamiku u njihovu turističku valorizaciju i upravljanje, što je rezultiralo time da su se u praksi kulturna dobra svodila na objekte kojima je potrebna zaštita. Zbog toga je u znanosti, ali i na tržištu, bio nužan novi pristup i svojevrstan uvod $\mathrm{u}$ tematiku, potpomognut potrebom kulturnih dobara i baštine za tržišnim prihodovanjem, s obzirom na smanjene lokalne, regionalne i državne potpore za kulturu, a $\mathrm{u}$ što nam uvid upravo daje knjiga "Kultura u izlogu" dr. sc. Daniele Angeline Jelinčić. 
DRUŠ. ISTRAŽ ZAGREB

GOD. 20 (2011)

STR. 271-290

Knjiga "Kultura u izlogu" autorice dr. sc. Daniele Angeline Jelinčić istodobno je sažet kratki vodič za upravljanje kulturnim dobrima i baštinom te svojevrstan predložak za planiranje, analizu, primjenu i kontrolu menadžerskih i marketinških znanja i vještina. Na aktualan i zanimljiv način autorica je obradila i iznijela atraktivnu problematiku važnu i za praktičare s područja kulture i za studente interdisciplinarnih područja (kulture i turizma), ali i za sve one zainteresirane iz širega čitateljstva.

Knjiga je pisana vrlo popularno i jednostavno, svima razumljivim jezikom, pa tako vrlo pojednostavnjeno razvija razmišljanje o marketingu kod svakoga pojedinca koji čita ovaj kratki vodič. Cilj i svrha knjige jesu pružiti osnove, tj. postavke, uspješna upravljanja kulturnim dobrima i baštinom u turističkom okruženju, što ne znači da knjiga daje konačna rješenja i smjernice kojih se kulturni menadžeri moraju pridržavati i za kojima se moraju voditi korak po korak. Prije svega, knjiga pruža svojevrstan okvir koji objašnjava "pravila igre", a specifičnost situacije kao i kreativnost kulturnih menadžera elementi su koji svakom procesu upravljanja daju razlikovnu notu i dodir osobnosti.

Izvori informacija i literatura prethodno su objavljeni istraživački radovi i dokumenti, sekundarni podaci te empirijska istraživanja i osobna iskustva. Osobna iskustva smatraju se osobito važnima i trebala bi poticati daljnje rasprave među kulturnim menadžerima te kulturnim i turističkim djelatnicima, jer bi se tako osiguralo pravilno i prikladno upravljanje brojnim kulturnim dobrima koja Hrvatska posjeduje, a time bi se ujedno uvela i dinamika u svakodnevni turistički život hrvatskih regija.
Knjiga je primarno namijenjena, zbog tematike koju obrađuje, menadžerima kulturnih dobara, konzervatorima, kulturnim i turističkim djelatnicima, kustosima, ali i stručnjacima za kulturni marketing, što ne znači da zaobilazi sekundarnu publiku, dapače, preporučuje se i kao nezaobilazna literatura za studente kulturnoga menadžmenta, ali i svih ostalih srodnih kulturnih ili turističkih usmjerenja.

Knjiga se sastoji od predgovora, uvoda, bibliografije, a podijeljena je u devet poglavlja u kojima se objašnjava proces upravljanja kulturnim dobrima i baštinom, kao i izazovi koje kulturni menadžeri na tom putu mogu očekivati.

U prvom poglavlju autorica objašnjava povijesni razvoj baštine, koji od koncepta vezanog uz obitelj prelazi u kolektivnu sferu. Kompleksnost samoga pojma baštine utječe i na njegovo definiranje, što dodatno otežava i moguća promjena vrijednosti što je baština može iskusiti tijekom vremena. Smatra se kako su bez primjerena upravljanja kulturna dobra i baština prepušteni polaganom, ali sigurnom, propadanju.

Koncept upravljanja kulturnom baštinom tema je drugoga poglavlja, u kojem se iznosi cilj upravljanja baštinom te objašnjava kako opseg baštine, odnosno vlasništvo nad kulturnim dobrima, mogu utjecati na mogućnost upravljanja baštinom. Naglašava se kako nije realno očekivati da se može i da će se očuvati baš svaki primjerak kulturnoga dobra i baštine, ali vrijedi uložiti trud i pokušati.

Povijesnu dimenziju i suvremenu upotrebu objekata baštine obuhvaća treće poglavlje knjige, u kojem je suvremena namjena grupirana kroz tri mogućnosti: društveno-administrativne, kulturne i ekonomske, a povijesna govori o prenamjeni objekata baštine $\mathrm{u}$ religiozne, vojne $\mathrm{i}$ industrijske objekte.

Tema četvrtoga poglavlja usredotočuje se na gospodarski pristup kulturnim dobrima, gdje se uz pozitivne izdvajaju i mogući negativni učinci turističke valorizacije kulturnih dobara i baštine, koji se o- 
DRUŠ. ISTRAŽ. ZAGREB

GOD. 20 (2011)

RECENZIJE | PRIKAZI

BR. 1 (1 111 ),

STR. $271-290$

čituju u komercijalizaciji kulture, invenciji tradicije i gubitku autentičnosti.

Peto poglavlje razmatra konzervaciju kulturnih dobara i baštine, gdje se objašnjava značenje konzervacije od prezervacije, restauracije, renovacije do regeneracije, jer se često u praksi može čuti pogrešna upotreba termina koji označavaju određeni tip konzervacije. Naglašava se važnost potrebe konzervacije i koncept baštine kao nositelja očuvanja kulturne raznolikosti. Posebno se naglašava kako manjak financijskih sredstava ili modernizacija (tzv. izazovi konzervacije) mogu utjecati na očuvanje kulturnih dobara, što se očituje već u samom procesu planiranja konzervacije.

O razlikama u upravljanju materijalnim i nematerijalnim kulturnim dobrima, kao i o načinu pristupa upravljanju ljudskim resursima, posjetiteljima i lokalnim stanovništvom govori šesto poglavlje. Neki stručnjaci smatraju da kulturna dobra ne treba povezivati s turizmom, svoju ulogu vide $u$ očuvanju baštine, a ne $u$ osiguranju javnoga pristupa kulturnim dobrima te ističu kako bi baština uistinu ispunila ulogu koju ima u društvu, odnosno kako bi bila očuvana za sadašnje i buduće generacije, nužno ju je prezentirati javnosti i publici. Što se tiče raznih vrsta potpora koje ne dolaze izravno, sve je popularniji način financiranja baštine sponzorstvo, koje uključuje novčana sredstva ili tzv. "in - kind" usluge (npr. besplatne karte, besplatan prostor $\mathrm{u}$ novinama $\mathrm{u}$ zamjenu za besplatne ulaznice), što su samo neki od izdvojenih primjera financiranja u ovom poglavlju i obično se razlikuju i dogovaraju od slučaja do slučaja.

Interpretacijom kulturnih dobara, iskustvom posjetitelja, ulogom kroz povi- jest bavi se sedmo poglavlje, gdje se naglašava važnost interpretacije kao kulturno osjetljivije komponente $\mathrm{u}$ izboru medija interpretacije. Smatra se kako je svrha interpretacije pomoći posjetiteljima $u$ doživljavanju kulturnih dobara te da se doživljavanje kulturnih dobara bez interpretacije uvelike razlikuje od onoga koje se služi interpretacijom. Budući da interpretacija ima edukativnu i zabavnu ulogu za posjetitelja, realno je očekivati da se interpretacija vodi motivom zarade, a uloga i planiranje interpretacije istodobno su važni i za iskustvo posjetitelja. U poglavlju se daje prikaz najjednostavnije podjele medija interpretacije na osobne i neosobne medije, pri čemu osobni mediji uključuju živu osobu kao aktualni medij prezentacije informacija, a neosobni mehanizmi i oprema ne zahtijevaju intervenciju osoblja, odnosno posjetitelja.

Strogu ekonomsku znanost razmatra osmo poglavlje knjige, s ciljem objašnjenja pojma marketinga, marketinškoga plana i miksa, ciljnoga tržišta i procesa planiranja marketinga. Budući da živimo u svijetu medija koji nas svakodnevno bombardiraju raznim porukama oglašivača kako bi povećali prodaju određenoga proizvoda, autorica smatra da kada se pak radi o marketingu kulturne baštine i o upravljanju kulturnim dobrima, čija je prvotna svrha očuvanje i zaštita prošlosti, marketing ne bi trebao biti usmjeren prije svega na povećanje broja posjetitelja, odnosno prodaje, dapače, marketing kulturnih dobara trebao bi se usredotočiti na ciljno tržište, kontrolu posjeta toga tržišta te na poboljšanje standarda konzervacije. Proces planiranja kulturnoga marketinga za kulturna dobra autorica je identificirala kroz pet stupnjeva planiranja, koje je preuzela od Halla i Mc Arthura (prema Timothy i Boyd, 2003., 185), i ističe kako je važno napraviti tzv. segmentaciju tržišta, postaviti marketinški cilj i strategiju, definirati i evaluirati promidžbu kako bi rezultat bio valjan.

Deveto poglavlje zaključuje i sažima prethodno iznesene tvrdnje i znanja o 
DRUŠ. ISTRAŽ ZAGREB GOD. 20 (2011),

STR. 271-290

upravljanju kulturnim dobrima koja nisu konačna, dapače, oni su osnova za daljnju kreativnost $i$ istraživanje vezano za upravljanje kulturnim dobrima! Autorica ističe i zaključuje kako je pojam kulturne baštine vrlo kompleksan, jer uključuje više razina koje zahtijevaju vrlo suptilan pristup, jer nije isto upravljati materijalnim i nematerijalnim dobrima, kao što nije isto upravljati kulturnim dobrima te onima koja uključuju i elemente prirodne baštine. Jednako tako i upravljanje kulturnim dobrima traži jedinstven pristup svakom pojedinom kulturnom dobru te prilagodbu specifičnim uvjetima, koji često određuju način upravljanja njime.

Mislim kako će knjiga "Kultura u izlogu" svojim interdisciplinarnim i inovativnim pristupom poslužiti kao primjer svim istraživačima, sadašnjima i budućima, kvalitetne dopune oskudne literature o upravljanju kulturnim dobrima i institucijama, ali i kao podloga i poticaj za nova istraživanja ne samo na području kulture nego i šire.

Rebeka Mesarić Žabčić

doi:10.5559/di.20.1.17

\section{Jonah Lehrer THE DECISIVE MOMENT. HOW THE BRAIN MAKES UP ITS MIND}

Canongate Books, Edinburgh, 2010., 294 str.

Knjiga mladoga američkog autora, psihologa Jonaha Lehrera, objavljena je pod dva naslova: početno, u SAD-u, pod naslovom How We Decide (Kako odlučujemo), a potom u identičnom britanskom džepnom izdanju pod naslovom Odlučan trenutak. Kako mozak donosi odluke. Oba naslova podjednako dobro opisuju sadržaj knjige. Prije objavljivanja ove knjige Lehrer je radio u laboratoriju nobelovca Erica Kandela, objavio je knjigu Proust kao neuroznanstvenik, a redovito piše za New Yorker, Washington Post i Boston Globe te uređuje blog Scientific Americana "Mind Matters" i piše vlastiti, vrlo cijenjeni blog The Frontal Cortex. Knjigu Kako odlučujemo (odnosno Odlučan trenutak) s pravom su pohvalili Oliver Sacks, Tom Vanderbilt, Antonio Damasio i Dan Ariely. Knjiga Odlučan trenutak nastavlja vrlo bogatu recentnu izdavačku djelatnost američkih nakladnika, ali i stil knjiga poput Arielyjevih Predvidljivo iracionalni i Prednosti iracionalnosti, Gigerenzerovih - Snage intuicije i Racionalnosti za smrtnike, Harfodovih - Ekonomist na tajnom zadatku i Logika života, Levitt-Dubnerove Freakonomije (i novije Superfrikonomije), Gladwellovih - Blink i Tipping Point, Thaler-Sunsteinove knjige Poticaj, Gilbertove knjige Mit o sreći, knjige braće Brafman Sway, Mlodinowljeve Korak pijanice, Talebova Crnog labuda ili starijih knjiga poput Damasiove Descartesove greške. (Naši izdavači u toj bujici zanimljivih znanstveno-popularnih knjiga drže dobar korak.)

Navedene knjige ocrtavaju razmjerno novo i nejasno ograničeno znanstveno područje pod imenom "bihevioralna ekonomija" ili psihologija odlučivanja, jednostavno: istraživanje standardnih (tipičnih) pogrešaka koje ljudi rade $u$ statističkom razmišljanju, ponašanju i posebno - pri odlučivanju. Od sedamdesetih godina, kada su nobelovci (2002.) Daniel Kahneman i Vernon Smith te Reinhardt Selten (1994.), ali posebno Kahneman i njegovi suradnici Tversky, Gilowich, Griffin, Slovic i dr., počeli eksperimentalno upozoravati na sistematske "poremećaje" naše racionalnosti, nije se iznjedrila sistematska teorija našega ponašanja i odlučivanja. Pri odlučivanju radimo tipične, sistemske pogreške, ali zašto do njih dolazi, kakva bi bila evolucijska svrha naše iracionalnosti, je li na- 